\title{
Determinants of Under-Five Mortality in High Mortality Regions of Ethiopia: An Analysis of the 2011 Ethiopia Demographic and Health Survey Data
}

\author{
Solomon Gebretsadik ${ }^{1}$ and Emmanuel Gabreyohannes ${ }^{2}$ \\ ${ }^{1}$ Department of Statistics, Jigjiga University, P.O. Box 1020, Jigjiga, Ethiopia \\ ${ }^{2}$ Econometric/Statistics, Ethiopian Civil Service University, Addis Ababa, Ethiopia \\ Correspondence should be addressed to Solomon Gebretsadik; solomonbereka@gmail.com
}

Received 31 March 2016; Revised 30 August 2016; Accepted 24 October 2016

Academic Editor: Sally Guttmacher

Copyright (C) 2016 S. Gebretsadik and E. Gabreyohannes. This is an open access article distributed under the Creative Commons Attribution License, which permits unrestricted use, distribution, and reproduction in any medium, provided the original work is properly cited.

\begin{abstract}
The study was a secondary analysis of existing data from the 2011 Ethiopia Demographic and Health Survey data. Of the 2097 live births recorded in Affar, Somali, Benishangul-Gumuz, and Gambela regions of Ethiopia between 2006 and 2011, 366 deaths before the age of five years were reported. The univariable and multivariable Cox proportional regression models were fitted to select the factors affecting under-five mortality in these regions. The model revealed that under-five mortality significantly associated with preceding birth interval, family size, birth type, breastfeeding status, source of drinking water, and income of mother. Children born after a preceding birth interval of 2-3 years and 3 years and above were significantly less likely to have died before their fifth birthday than those born within two years. Children who were breastfed, for any period, were 25.5\% (HR 1.255, 1.005$1.567, p=0.045)$ less likely to have died before their fifth birthday than those who were not breastfed. Increased birth interval time corresponds to a low probability of child mortality. Thus, mothers should be encouraged to wait for a sufficient number of months after a birth to conceive another child. Furthermore, breastfeeding was of paramount importance in the fight against child mortality.
\end{abstract}

\section{Background}

Under-five mortality is a leading indicator of child health and overall development of a nation, as it reflects the social, economic, and environmental conditions in which children (and others in society) live, including their healthcare [1].

Worldwide, 5.9 million children below five years of age died in 2015. The risk of a child dying before completing five years of age is still the highest in the World Health Organization (WHO) African countries (81 per 1000 live births), about 7 times higher than in the WHO European region (11 per 1000 live births). Low-income countries reported 76 deaths per 1000 live births, about 11 times the average rate in highincome countries (7 deaths per 1000 live births) [2]. SubSaharan Africa continues to confront significant challenges, as the region with the highest child mortality rates in the world: 98 deaths per 1,000 live births in 2012. All 16 countries with an under-five mortality rate above 100 deaths per 1,000 live births are in sub-Saharan Africa [3]. While progress in child health has been made over the past five years in Ethiopia with the under-five mortality rate reducing from 123 to 88 deaths per 1,000 live births, the death rate is intolerably high as one in 11 children did not live beyond their fifth birthday [4]. In addition, some regions in Ethiopia are characterized by higher rates of child mortality. For instance, according to 2011 Ethiopia Demographic and Health Survey (2011 EDHS) data, under-five mortality rates per 1000 live births for Affar were 127, for Somali were 122, for Benishangul-Gumuz were 169, and for Gambela were 123 for the year 2010/2011 [4]. Thus, this study tries to explore the major risk factors of underfive mortality taking into consideration various demographic, 
TABLE 1: Description of socioeconomic, demographic, and environment related covariates.

\begin{tabular}{lccc}
\hline Number & Description and name & Notation & Categories \\
\hline$(1)$ & Sex of child & SEX & $1=$ male, $2=$ female \\
$(2)$ & Type of birth & BTYPE & $0=$ single birth, $1=$ multiple births \\
$(3)$ & Mother's age at first birth of child & MAGEB & $0=\leq 16$ years, $1=>16$ years \\
$(4)$ & Family size & FSIZE & $0=1-3$ members, $1=4-6$ members, $2=\geq 7$ members \\
$(5)$ & BFDINGS & $0=$ no, $1=$ yes \\
$(6)$ & PBITVAL & $0=\leq 2$ years, $1=2-3$ years, $2=\geq 3$ years \\
$(7)$ & Preceding birth interval & MEDU & $0=$ no education, $1=$ primary and above \\
$(8)$ & Mother's education & FEDU & $0=$ no education, $1=$ primary and above \\
$(9)$ & Father's education & ARISD & $1=$ urban, $2=$ rural \\
$(10)$ & Area of residence & MSTAT & $0=$ married, $1=$ not married \\
$(11)$ & Marital status & MINCOM & $0=$ more than husband, $1=$ less than husband \\
$(12)$ & Income of mother relative to her husband & SDWTR & $0=$ pipe, $1=$ others \\
\hline
\end{tabular}

socioeconomic, and environmental factors in these regions of Ethiopia.

Child health is determined by many factors including parental education, access to health services, and income of families [5]. According to Mosley and Chen (1984), child mortality is determined by a combination of socioeconomic, biological, environmental, and behavioral factors [6].

Earlier studies conducted in Brazil, Kenya, and southwest Ethiopia reported that under-five mortality is influenced by socioeconomic status [7-9], birth weight [10], mother's age [8], place of residence, mother's age, mother's education, place of delivery, birth order, sex of child, religion of parents, household headship, and household socioeconomic status [11-15].

\section{Methods}

2.1. Source of Data. The 2011 EDHS is the third DHS in Ethiopia, following the 2000 and 2005 EDHS surveys. The 2011 EDHS used a two-stage stratified sampling technique to select a sample of households for the data collection. In the first stage, 624 enumeration areas were randomly selected: 187 in urban areas and 437 in rural areas. In the second stage, a fixed number of 30 households were selected for each EA. Of the 18,720 selected households, 5,610 were in urban areas and 13,110 were in rural areas. All women aged 15-49, living permanently in the selected households or present in the household on the night before the survey visit, were eligible to be interviewed in the EDHS. In 2011 EDHS, a total of 17,385 eligible women were identified and interviews were completed for 16515 women, yielding a response rate of 95 percent. Information for this study was taken from the birth history section of the 2011 EDHS Women's Questionnaire.

2.2. Study Design. The study design was a retrospective study which analyzed data from the 2011 EDHS.

2.3. Study Population. The study population was all women who had given birth to a live infant in the preceding 5 years.
2.4. Data Availability. The DHS data used for this study are openly available and can be downloaded from http://www .measuredhs.com/data/available-datasets.cfm?inputSearch= ETHIOPIA.

\subsection{Variables in the Study}

2.5.1. The Dependent Variable. The dependent variable of the study is duration of time from date of birth until date of death or censor (if the child survives past 59 months).

2.5.2. Explanatory (Covariates) Variables. The main predictors explored for under-five mortality for this study were taken from Mosley and Chen (1984) determinants of childhood morbidity and mortality framework for developing countries [6], similar studies, and available data on the subject. We grouped them into demographic, socioeconomic, and environmental factors. All are presented in Table 1.

2.6. Method of Data Analysis. In this study, survival analysis was conducted to find out the determinants of under-five mortality in four selected regions of Ethiopia. This comprised Kaplan-Meier with log-rank test and Cox proportional hazard regression model. The data analysis was done using SPSS 20, STATA, and SAS statistical (software) packages.

2.7. Ethical Considerations. The protocol for the EDHS was approved by the Ethiopia Health and Nutrition Research Institute Review Board, National Research Ethics Review Committee (NRERC) at the Federal Democratic Republic of Ethiopia Ministry of Science and Technology, the Institutional Review Board of ICF Macro, and the Centers for Disease Control and Prevention (CDC) in Atlanta.

\section{Results}

The results of the analysis were divided into four sections: descriptive analysis of survival data results, result of log-rank 
TABLE 2: Summary of some important socioeconomic, demographic, and environmental characteristics of children in four selected regions of Ethiopia, 2011.

\begin{tabular}{|c|c|c|c|c|c|}
\hline Covariates & Category & Censored & Death & Death percent & Total \\
\hline \multirow{2}{*}{ Child's sex } & 1 (male) & 869 & 184 & 17.5 & 1053 \\
\hline & 2 (female) & 862 & 182 & 17.4 & 1044 \\
\hline \multirow{2}{*}{ Mother's age at first birth } & $0(\leq 16)$ & 775 & 176 & 18.5 & 951 \\
\hline & $1(>16)$ & 956 & 190 & 16.6 & 1146 \\
\hline \multirow{2}{*}{ Breastfeeding status } & $0($ no) & 932 & 233 & 20.0 & 1165 \\
\hline & 1 (yes) & 799 & 133 & 14.3 & 932 \\
\hline \multirow{2}{*}{ Mother's education } & 0 (no education) & 1314 & 301 & 18.6 & 1615 \\
\hline & 1 (primary and above) & 417 & 65 & 13.5 & 482 \\
\hline \multirow{2}{*}{ Father's education } & 0 (no education) & 1000 & 227 & 18.5 & 1227 \\
\hline & 1 (primary and above) & 731 & 139 & 16.0 & 870 \\
\hline \multirow{2}{*}{ Marital status } & 0 (married $)$ & 1670 & 349 & 17.3 & 2019 \\
\hline & 1 (others) & 61 & 17 & 22.0 & 78 \\
\hline \multirow{3}{*}{ Preceding birth interval } & $0(\leq 2$ years $)$ & 574 & 204 & 26.0 & 778 \\
\hline & 1 (2-3 years) & 535 & 103 & 16.0 & 638 \\
\hline & 2 ( $\geq 3$ years $)$ & 622 & 59 & 9.0 & 681 \\
\hline \multirow{2}{*}{ Area of residence } & 1 (urban) & 362 & 59 & 14.0 & 421 \\
\hline & 2 (rural) & 1369 & 307 & 18.3 & 1676 \\
\hline \multirow{2}{*}{ Type of birth } & 0 (single birth) & 1668 & 329 & 16.5 & 1997 \\
\hline & 1 (multiple births) & 63 & 37 & 37.0 & 100 \\
\hline \multirow{2}{*}{ Income of mother } & 0 (more than husband) & 291 & 76 & 21.0 & 367 \\
\hline & 1 (less than husband) & 1440 & 290 & 17.0 & 1730 \\
\hline \multirow{2}{*}{ Source of drinking water } & 0 (pipe) & 344 & 46 & 12.0 & 390 \\
\hline & 1 (others) & 1387 & 320 & 18.7 & 1707 \\
\hline \multirow{3}{*}{ Family size } & $0(1-3)$ & 852 & 130 & 13.2 & 982 \\
\hline & $1(4-6)$ & 775 & 193 & 19.9 & 968 \\
\hline & $2(\geq 7)$ & 104 & 43 & 29.2 & 147 \\
\hline
\end{tabular}

result, univariable analysis results, and result of multivariable analysis.

3.1. Descriptive Analysis. The total numbers of live births considered for this study were 2097 with 366 deaths occurring before the age of 5 years. Of the total live births, $17.5 \%$ and $17.4 \%$ of under-five deaths have occurred for males and females, respectively. Regarding mothers' age at birth, $43.4 \%$ of children were from mothers of age less than 16 years, out of whom $18.5 \%$ died before the age of five years, while the remaining $54.6 \%$ were from mothers aged 17 years and above, out of whom $16.6 \%$ have died before the age of five years. The under-five mortality was $18.6 \%$ and $13.5 \%$ for children whose mothers have no education and primary and above education, respectively. Almost two-thirds (65.3\%) of the children were born to mothers resident in rural areas, with $18.3 \%$ dying before their fifth birthday. Of the 421 children born to mothers resident in urban areas, $14.0 \%$ died before their fifth birthday. Of the total of 2097 children, $44.4 \%$ were breastfed. Among the mothers, $79.6 \%$ were married. There were $46.8 \%$ households of size 1-3 members, $46.2 \%$ had household size of $4-6$, and $7.0 \%$ of the households had more than 6 members. In addition, $18.6 \%$ of the households had pipe home water while $81.4 \%$ used water from unprotected source. Finally, children

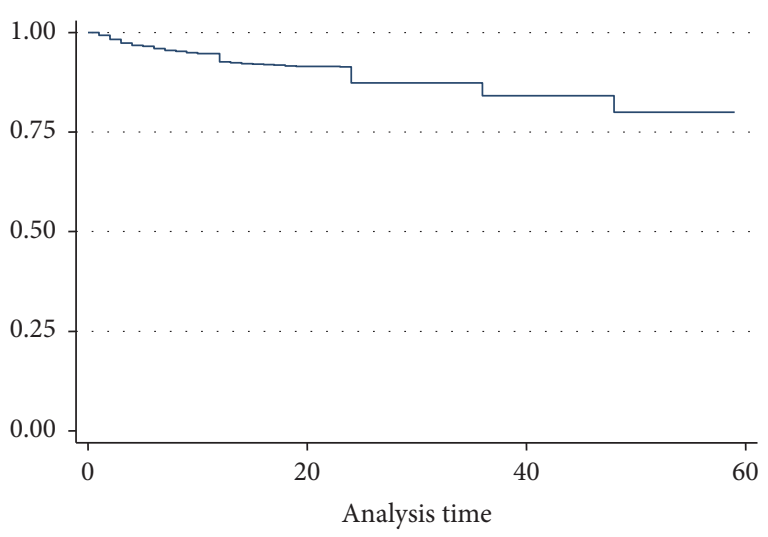

FIGURE 1: Overall product limit estimate of survival function.

with preceding birth interval shorter than 2 years were subject to higher risk of under-five mortality (26\%). All the results have been summarized in Table 2 .

The plot of overall Kaplan-Meier estimate indicated that, for children who were born in the four selected regions of Ethiopia, under-five death relatively decreased as follow-up time increased (Figure 1). 
TABLE 3: Result of log-rank test of equality of survival distribution for the different categorical covariates.

\begin{tabular}{lccc}
\hline Covariates & Chi-square & df & $p$ value \\
\hline Preceding birth interval & 72.531 & 2 & 0.000 \\
Family size & 31.205 & 2 & 0.000 \\
Type of birth & 38.874 & 1 & 0.000 \\
Breastfeeding status & 10.719 & 1 & 0.001 \\
Source of drinking water & 9.445 & 1 & 0.002 \\
Mother's education & 6.185 & 1 & 0.013 \\
Income of mother & 3.989 & 1 & 0.046 \\
Area of residence & 3.243 & 1 & 0.072 \\
Father's education & 2.017 & 1 & 0.156 \\
Marital status & 1.644 & 1 & 0.200 \\
Mother's age at first birth & 1.598 & 1 & 0.206 \\
Sex of child & 0.001 & 1 & 0.972 \\
\hline
\end{tabular}

The log-rank test was performed to see whether there is a significant difference among survival experiences of two or more groups of the covariates (Table 3 ).

From Table 3, we can see that the covariates, namely, preceding birth interval, family size, type of birth, breastfeeding status, source of drinking water, mothers' educational level, and income of mothers, exhibit a significant difference in the survival experience among their categories at the 5\% level of significance; that is, the hazard of child mortality for these covariates varies significantly from group to group.

3.2. Bivariate Analyses. We start with fitting univariable Cox proportional hazards regression model. Table 4 displays summarized result obtained from SAS and SPSS output of univariable analysis.

From Table 4, we can identify candidate covariates to be considered for the multivariable model. Inclusion of covariates was based on a significant reduction in the value of $-2 \log \widehat{L}$. The value of $-2 \log \widehat{L}$ for the null model is 5348.115. Including preceding birth interval, family size, type of birth, breastfeeding status, source of drinking water, and mothers' educational level in the model, one at a time, resulted in a significant reduction in $-2 \log \widehat{L}$ using the chi-square test. Also, the covariates income of mothers, area of residence, and fathers' educational level are significant at the $20 \%$ level of significance. Hence, all these covariates were considered in the multivariable Cox regression model. We then applied stepwise variable selection procedure to obtain the reduced model. All are presented in Table 5.

Preceding birth interval has a significant negative association with under-five mortality. Children born 2-3 years and more than 3 years after the previous birth have a reduced risk of child mortality by 39 and 69 percent, respectively, relative to children born less than 2 years after the previous birth.

Mortality risk of child increased as size of family increases. The risk of dying for a child born in a family of size 4-6 was higher by $71.5 \%$ relative to those born in a family with size of 1-3 (reference category). Children born in a family with size of seven and above have a significantly higher hazard ratio than children born in a family with size of 1-3; that is, children born in a family of size seven and above were $152.4 \%$ more likely to die before the age of five as compared with children in the reference category.

Type of birth (single versus multiple) was also a significant predictor of under-five mortality. Children of multiple births were $190.7 \%$ more likely to die before the age of 5 relative to the reference group of single birth $(\mathrm{HR}=2.907$, 95\% CI: 2.060-4.102, $p=0.000)$.

Children who were not breastfed were $25.5 \%$ more likely to die before their fifth birthday.

The risk of dying for a child born in a family without access to pipe drinking water was higher by $72.7 \%$ relative to those born in a family with access to pipe drinking water.

The risk of under-five mortality for a child whose mother earns less than her husband was higher by $43.9 \%$ relative to a child whose mother earns more than her husband (reference category) ( $\mathrm{HR}=1.439,95 \% \mathrm{CI}: 1.109-1.866, p=0.006)$.

\section{Discussion}

In this study, the covariates, namely, preceding birth interval, family size, birth type, breastfeeding status, source of drinking water, mother education, mother income, area of residence, and father education, are significantly associated with under-five mortality in univariable analysis but in multivariable analysis we obtained six factors, namely, preceding birth interval, family size, type of birth, breastfeeding status, source of drinking water, and income of mothers, to significantly affect the survival of under-five children.

The result of this study shows that preceding birth interval has a negative association with under-five mortality. A study in Ethiopia showed that children born after 18-23, 24-35, 36-47, and more than 47 months of the preceding birth intervals have lower risk of child mortality by 49, 78, 79, and 89 percent, relative to children born after less than 18 months, respectively [16]. A similar study based on DHS data from Bolivia, Guatemala, and Peru suggested that underfive mortality in children born after birth intervals of 24-29 months was higher by 70-90\% than in children born after intervals of 36-41 months [17]. In Bangladesh, a study showed that if all birth intervals were between 3 and 5 years long, early neonatal mortality would fall by $5.8 \%$, late neonatal mortality by $4 \%$, postneonatal mortality by $7.6 \%$, and mortality in the $1-4$-year age group by $8.7 \%$ [18]. This may be due to the fact that shorter birth intervals are associated with maternal nutritional depletion, particularly folate deficiency.

There is a higher under-five death among children who were not breastfed than those breastfed. A study conducted in Kenya showed that children who were breastfed for more than 6 months have significantly lower probability $(p<0.05)$ of mortality compared to children breastfed for less than 6 months [10]. Also, in Bangladesh, a study revealed that the duration of breastfeeding was an important determinant of childhood mortality [19]. This may be due to the fact that antimicrobial and anti-inflammatory factors in breast milk provide protection from infection.

The findings of this study also revealed that family size was a significant determinant of under-five mortality. As 
TABLE 4: Results of the univariable proportional hazards Cox regression model.

\begin{tabular}{|c|c|c|c|c|c|c|c|c|c|}
\hline Covariates & $B$ & SE & Wald $\chi^{2}$ & $\mathrm{df}$ & Sig. & $\exp (B)$ & $\operatorname{LR} \chi^{2}$ & Sig. & $-2 \log L$ \\
\hline \multicolumn{10}{|l|}{ PBITVAL } \\
\hline ( $\leq 2$ years $)$ & & & 64.519 & 2 & 0.000 & & 65.9208 & $<.0001$ & 5275.450 \\
\hline $2-3$ years & -0.491 & 0.121 & 16.470 & 1 & 0.000 & 0.612 & & & \\
\hline$\geq 3$ years & -1.150 & 0.148 & 60.516 & 1 & 0.000 & 0.317 & & & \\
\hline \multicolumn{10}{|l|}{ FSIZE } \\
\hline$(1-3)$ & & & 29.093 & 2 & 0.000 & & 29.1003 & $<.0001$ & 5319.890 \\
\hline $4-6$ & 0.437 & 0.113 & 14.837 & 1 & 0.000 & 1.548 & & & \\
\hline$\geq 7$ & 0.874 & 0.176 & 24.688 & 1 & 0.000 & 2.397 & & & \\
\hline BTYPE (single birth) & 1.019 & 0.174 & 34.418 & 1 & 0.000 & 2.770 & 34.4193 & $<.0001$ & 5321.649 \\
\hline BFDINGS (yes) & 0.348 & 0.109 & 10.251 & 1 & 0.001 & 1.416 & 10.2506 & 0.0014 & 5337.582 \\
\hline SDWTR (pipe) & 0.472 & 0.158 & 8.958 & 1 & 0.003 & 1.603 & 8.9579 & 0.0028 & 5338.051 \\
\hline $\begin{array}{l}\text { MEDU (primary and } \\
\text { above) }\end{array}$ & 0.333 & 0.137 & 5.920 & 1 & 0.015 & 1.395 & 5.9110 & 0.0150 & 5341.767 \\
\hline $\begin{array}{l}\text { MINCOM (more } \\
\text { than husband) }\end{array}$ & -0.252 & 0.129 & 3.834 & 1 & 0.050 & 1.287 & 3.8381 & 0.0501 & 5344.469 \\
\hline ARSID (urban) & 0.251 & 0.142 & 3.117 & 1 & 0.077 & 1.285 & 3.1141 & 0.0776 & 5344.819 \\
\hline $\begin{array}{l}\text { FEDU (primary and } \\
\text { above) }\end{array}$ & 0.150 & 0.108 & 1.944 & 1 & 0.163 & 1.162 & 1.9443 & 0.1632 & 5346.149 \\
\hline
\end{tabular}

PBITVAL: preceding birth interval; FSIZE: family size; BTYPE: type of birth; BFDINGS: breastfeeding status; SDWTR: source of drinking water; MEDU: mother's education; MINCOM: income of mother; ARISD: area of residence; FEDU: father's education.

TABLE 5: Parameter estimates of the final model.

\begin{tabular}{|c|c|c|c|c|c|c|c|c|c|c|}
\hline \multirow{2}{*}{ Covariates } & \multirow{2}{*}{$B$} & \multirow{2}{*}{ SE } & \multirow{2}{*}{ Wald $\chi^{2}$} & \multirow{2}{*}{$\mathrm{df}$} & \multirow{2}{*}{ Sig. } & \multirow{2}{*}{$\exp (B)$} & \multirow{2}{*}{$\operatorname{LR} \chi^{2}$} & \multirow{2}{*}{ Sig. } & \multicolumn{2}{|c|}{$95 \%$ CI for $\exp (B)$} \\
\hline & & & & & & & & & Lower & Upper \\
\hline \multicolumn{11}{|l|}{ PBITVAL } \\
\hline ( $\leq 2$ years $)$ & & & 67.192 & 2 & 0.000 & & 68.338 & $<.0001$ & & \\
\hline 2-3 years & -0.499 & 0.121 & 16.958 & 1 & 0.000 & 0.607 & & & 2.435 & 4.358 \\
\hline$\geq 3$ years & -1.181 & 0.149 & 63.226 & 1 & 0.000 & 0.307 & & & 1.436 & 2.726 \\
\hline \multicolumn{11}{|l|}{ FSIZE } \\
\hline$(1-3)$ & & & 33.005 & 2 & 0.000 & & 33.491 & $<.0001$ & & \\
\hline $4-6$ & 0.926 & 0.184 & 25.326 & 1 & 0.000 & 1.715 & & & 1.361 & 2.162 \\
\hline$\geq 7$ & 0.540 & 0.118 & 20.882 & 1 & 0.000 & 2.524 & & & 1.760 & 3.620 \\
\hline BTYPE (single birth) & -1.067 & 0.176 & 36.894 & 1 & 0.000 & 2.907 & 37.054 & $<.0001$ & 2.060 & 4.102 \\
\hline BFDINGS (yes) & 0.227 & 0.113 & 4.013 & 1 & 0.045 & 1.255 & 12.212 & 0.0005 & 1.005 & 1.567 \\
\hline SDWTR (pipe) & -0.546 & 0.159 & 11.797 & 1 & 0.001 & 1.727 & 7.107 & 0.0077 & 1.264 & 2.358 \\
\hline $\begin{array}{l}\text { MINCOM (more than } \\
\text { husband) }\end{array}$ & 0.364 & 0.133 & 7.518 & 1 & 0.006 & 1.439 & 4.124 & 0.0423 & 1.109 & 1.866 \\
\hline
\end{tabular}

expected, the number of family members increased the under-five death rate; that is, the risk of dying for a child born in a family of size 4-6 is higher by $71 \%$ relative to those born in a family with size of 1-3. Contrarily, the study by Desta carried out in Ethiopia found an inverse relationship between underfive mortality and family size [16]. This discrepancy could be due to the time gap between the current study and the study conducted by Desta [16].

The result also showed that multiple birth type was a significant factor for under-five death in four selected regions in Ethiopia. Children of multiple births were 2.907 more likely to die before the age of 5 as compared with single birth. In Ethiopia, a study by Desta found multiple births to be a significant determinant factor [16]. A study carried out by Kembo and Van Ginneken in Zimbabwe also found multiple births as a determinant factor of under-five mortality [20].

This study showed that the source of drinking water was significant. A child born in a family without access to pipe drinking water was highly exposed to under-five death. In Kenya, a study by Mutunga found source of drinking 
water to be a determinant factor [21]. A study in China showed that access to safe water reduced child mortality risks by about $34 \%$ in rural areas [22]. This may explain why children exposed to water sources that are more likely to be contaminated such as river water are more likely to have diarrheal diseases.

This study revealed that the risk of under-five mortality for a child whose mother earns less than her husband is higher as compared with those who earn more. This could be due to the fact that mothers who earn more have the chance to spend money any time they wish without waiting for their husbands to provide care for their child. In Bangladesh, a study by Abir et al. found income of mother to be a determinant factor [23].

In every country studied and regardless of the period under consideration, mothers' education turned out to be one of the main determinants of the mortality of children aged from 1 to 5 years. Findings from [24] suggested that education in general, and female education in particular, exerts a great influence on children's health and survival with regard to pregnancy, childbirth, immunization, and management of childhood diseases. Mothers' educational level increases their skills in healthcare practices related to disease treatment, preventive care, hygiene, and nutrition, thus improving chances for child survival. A study in Kenya showed that deaths among under-five children differed significantly with the level of maternal education in rural areas compared with urban areas $(p<0.001)$ [21]. In addition, other studies [20-22] revealed that women with low educational level have high rates of infant and child mortality and those with a few years of schooling have lower infant and child mortality rates.

In conclusion, the finding of this study agreed, to a great extent, with the finding of the studies discussed above. However, in this study, mother's educational level was not found to be a determinant factor, a result that was not in line with other studies [17, 24-27]. Moreover, the finding discussed above about family size is opposite to Desta's finding [16]. This discrepancy could be due to the time gap between the current study and the study conducted by Desta [16].

This study was conducted based on 2011 EDHS data. The data is large, nationally representative sample of all deaths based on household interviews with families. The study results reflect the whole of the selected regions. Despite these strengths, a number of weaknesses were also present in this study. The birth history section of 2011 EDHS begins with questions about the respondent's experience with childbearing (i.e., the number of sons and daughters living with the mother, the number who live elsewhere, and the number who have died). Hence, 2011 EDHS was subject to possible data collection errors (e.g., only surviving women aged 15-49 were interviewed); therefore, no data were available for children of women who had died. Respondents were likely to forget events that occurred in the past. Also, causal effects could not be measured because the study was based on a retrospective cross-sectional study.

We recommended that further investigation has to be done based on the 2016/2017 EDHS in order to make the finding of this research more strong.

\section{Conclusions}

Our analysis of determinants of under-five mortality in four selected regions of Ethiopia revealed that preceding birth interval, family size, type of birth, breastfeeding status, source of drinking water, and income of mothers were the significant determinants. However, mothers' education and mothers' age at birth were found to be insignificant factors of under-five morality in these regions, a result which is not in line with the literature. In this study, this could be because the majority (77.01\%) of mothers involved had no education.

\section{Abbreviations \\ CI: Confidence interval \\ DHS: Demographic and Health Survey \\ EA: Enumeration area \\ HR: Hazard ratio \\ WHO: World Health Organization.}

\section{Competing Interests}

The authors declare that they have no competing interests.

\section{Authors' Contributions}

Solomon Gebretsadik and Emmanuel Gabreyohannes participated in all steps of the study from its beginning to the end. Solomon Gebretsadik has made substantive contribution to the acquisition, analysis, and interpretation of data. Emmanuel Gabreyohannes participated in the conception of the study, provided methodological guidance, supervised the analysis, and participated in drafting the manuscript. All authors read and approved the final manuscript.

\section{Acknowledgments}

The authors would like to express their deepest gratitude and appreciation to the Central Statistical Agency of Ethiopia for their warm welcome and for providing necessary information and data for the realization of the research.

\section{References}

[1] J. W. McGuire, "Basic health care provision and under-5 mortality: a cross-national study of developing countries," World Development, vol. 34, no. 3, pp. 405-425, 2006.

[2] World Health Organization, Report, Global health observatory (GHO) data, 2015, http://www.who.int/gho/child_health/ health/mortality/mortality_under_five_text/en/.

[3] United Nations, The Millennium Development Goals Report 2013, 2013, http://www.un.org/millenniumgoals/pdf/report2013/mdg-report-2013-english.pdf.

[4] Central Statistical Agency, Ethiopian Demographic and Health Survey 2011, Ethiopia Central Statistical Agency and ORC Macro, Addis Ababa, Ethiopia, 2012.

[5] S. B. Adebayo and L. Fahrmeir, "Analysing child mortality in Nigeria with geoadditive discrete-time survival models," Statistics in Medicine, vol. 24, no. 5, pp. 709-728, 2005. 
[6] W. Mosley and L. Chen, "An analytical framework for the study of child survival in developing countries," Population and Development Review, vol. 10, pp. 25-45, 1984.

[7] C. J. Machado and K. Hill, "Early infant morbidity in the City of São Paulo, Brazil," Population Health Metrics, vol. 1, article 7, 2003.

[8] H. Mustafa, "Socioeconomic determinants of infant mortality in Kenya: analysis of Kenya DHS 2003," International Journal of Humanities and Social Science, vol. 2, no. 2, p. 1934-722, 2008.

[9] M. Assefa, R. Drewett, and F. Tessema, "A birth cohort study in south west Ethiopia to identify factors associated with infant mortality that are amenable for intervention," Ethiopian Journal of Health Development, vol. 16, pp. 13-20, 2003.

[10] R. E. Black, S. S. Morris, and J. Bryce, "Where and why are 10 million children dying every year?" The Lancet, vol. 361, no. 9376, pp. 2226-2234, 2003.

[11] R. Adhikari and C. Podhisita, "Household headship and child death: Evidence from Nepal," BMC International Health and Human Rights, vol. 10, no. 1, article 13, 2010.

[12] R. R. Ettarh and J. Kimani, "Determinants of under-five mortality in rural and urban Kenya," Rural and Remote Health, vol. 12, no. 1, article 1812, 2012.

[13] H. V. Doctor, "Does living in a female-headed household lower child mortality? The case of rural Nigeria," Rural and Remote Health, vol. 11, no. 2, article 1635, 2011.

[14] I. E. Swenson, N. M. Thang, P. B. San, V. Q. Nham, and V. D. Man, "Factors influencing infant mortality in Vietnam," Journal of Biosocial Science, vol. 25, no. 3, pp. 285-302, 1993.

[15] T. Teka, A. S. G. Faruque, and G. J. Fuchs, "Risk factors for deaths in under-age-five children attending a diarrhoea treatment centre," Acta Paediatrica, International Journal of Paediatrics, vol. 85, no. 9, pp. 1070-1075, 1996.

[16] M. Desta, Infant and Child Mortality in Ethiopia: The role of Socioeconomic, Demographic and Biological factors In the previous five years period of 2000 and 2005 [M.S. thesis], Lund University, Lund, Sweden, 2011.

[17] S. O. Rutstein, "Effects of preceding birth intervals on neonatal, infant and under-five years mortality and nutritional status in developing countries: evidence from the demographic and health surveys," International Journal of Gynecology and Obstetrics, vol. 89, supplement 1, pp. S7-S24, 2005.

[18] J. DaVanzo, L. Hale, A. Razzaque, and M. Rahman, "Socioeconomic determinants of neonatal, post neonatal, infant and child mortality in Bangladesh," International Journal of Sociology and Anthropology, vol. 2, no. 6, pp. 118-125, 2004.

[19] M. Shahidullah, "Breast-feeding and child survival in Matlab, Bangladesh," Journal of Biosocial Science, vol. 26, no. 2, pp. 143154, 1994.

[20] J. Kembo and J. K. Van Ginneken, "Determinants of infant and child mortality in Zimbabwe: results of multivariate hazard analysis," Demographic Research, vol. 21, pp. 367-384, 2009.

[21] C. Mutunga, Environmental Determinants of Child Mortality in Kenya, . Kenya Institute for Public Policy Research and Analysis (KIPPRA), Nairobi, Kenya, 2004.

[22] H. Jacoby and L. Wang, Environmental Determinants of Child Mortality in Rural China: A Competing Risks Approach, World Bank, Washington, DC, USA, 2003.

[23] T. Abir, K. E. Agho, A. N. Page, A. H. Milton, and M. J. Dibley, "Risk factors for under-5 mortality: evidence from Bangladesh demographic and health survey, 2004-2011," BMJ Open, vol. 5, no. 8, Article ID e006722, 2015.
[24] J. C. Caldwell, "Education as a factor in mortality decline: an examination of Nigerian data," Population Studies, vol. 33, no. 3, pp. 395-413, 1979.

[25] D. Amare, G. Belaineh, and T. Fasil, "Determinants of underfive mortality in Gilgel Gibe Field Research Center, Southwest Ethiopia," Ethiopian Journal of Health Development, vol. 21, no. 2, pp. 117-124, 2007.

[26] K. Kyei, "Socio-economic factors affecting under five mortality in South Africa-an investigative study," Journal of Emerging Trends in Economics and Management Sciences, vol. 2, no. 2, pp. 104-110, 2011.

[27] H. Frank, T. Mekonen, and V. Paolo, Infant and Child Mortality in Urban Ethiopia: With Special Reference to Socio-demographic and Housing Conditions in Urban Areas and Addis Ababa, Italian Multi-Bi Research Project ETH/92/P01, Institute for Population Research - National Research Council (Irp-Cnr), Roma, Italy, 2001. 


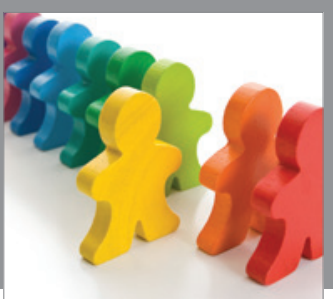

Autism

Research and Treatment
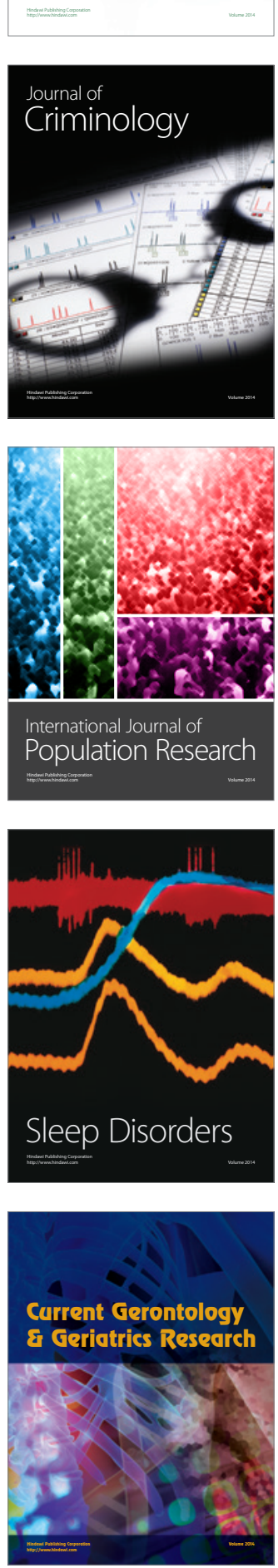

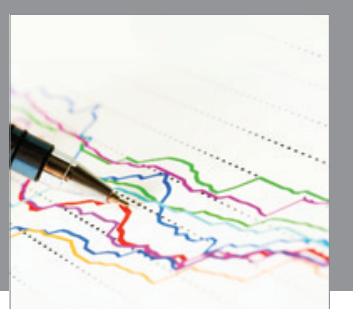

Economics

Research International
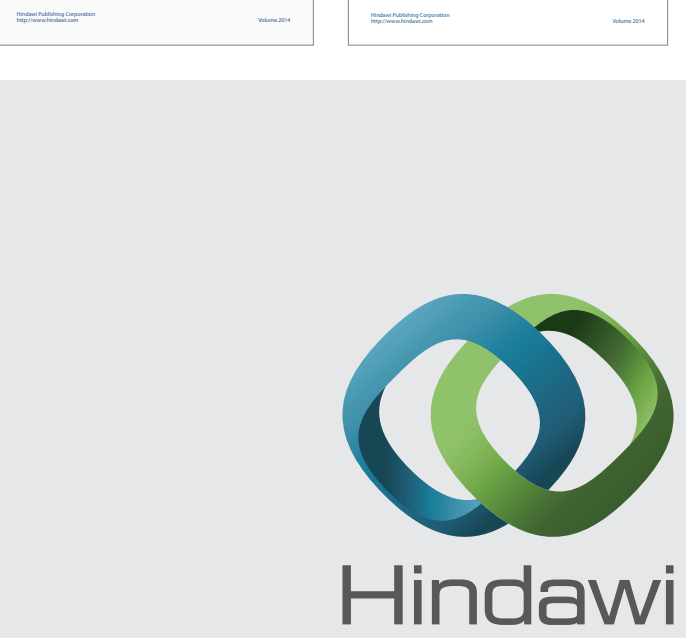

Submit your manuscripts at

http://www.hindawi.com
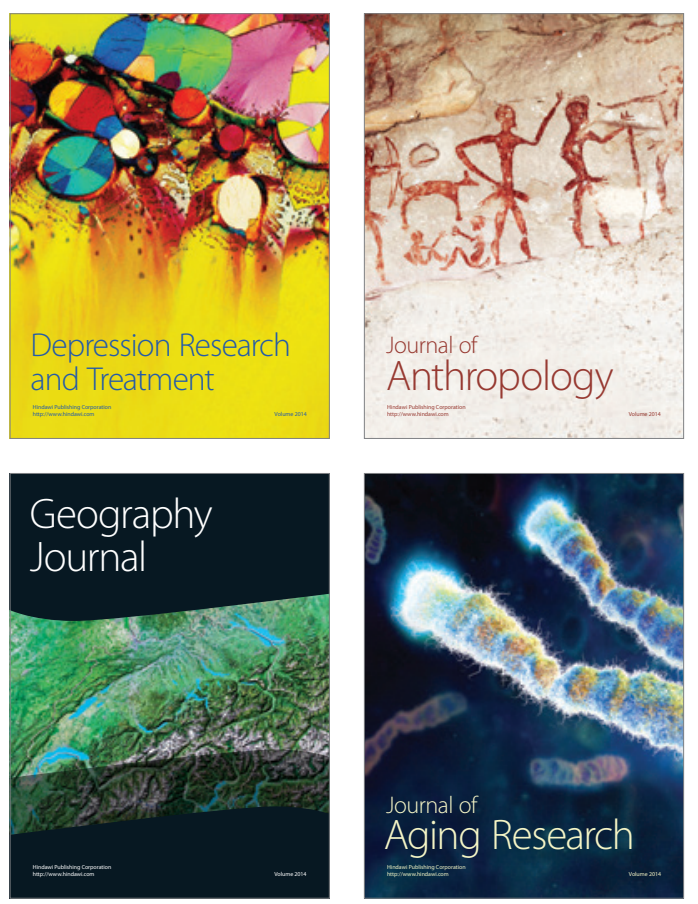
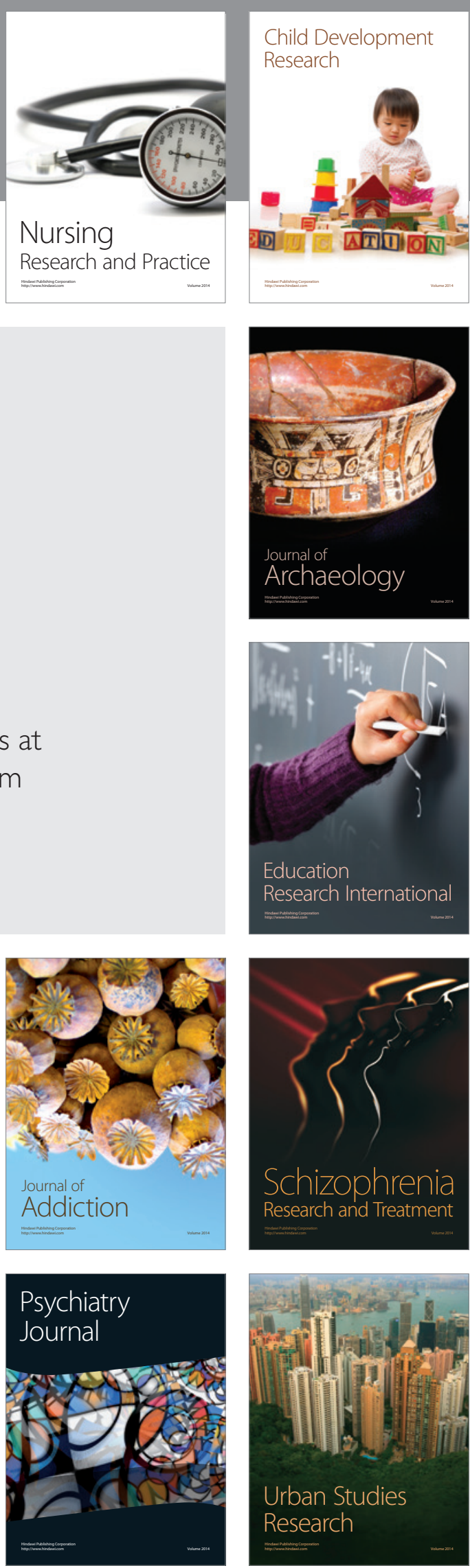